International Journal of Medical Sciences

ISSN 1449-1907 www.medsci.org 2006 3(2):75-78

Review

\title{
Antiviral therapy of HCV in the cirrhotic and transplant candidate
}

\author{
Steven K. Herrine, and Victor J. Navarro \\ Division of Gastroenterology and Hepatology, Thomas Jefferson University, 132 S. $10^{\text {th }}$ Street, Suite 450, Philadelphia, PA 19107 , \\ USA.
}

Corresponding address: Steven K. Herrine, MD, Division of Gastroenterology and Hepatology, Thomas Jefferson University, 132 S. $10^{\text {th }}$ Street, Suite 450, Philadelphia, PA 19107, USA. Telephone: 215.955.5247 Fax: 215.503.2146 Email: steven.herrine@jefferson.edu

Received: 2005.12.30; Accepted: 2006.03.01; Published: 2006.04.01

Despite the improved efficacy of peginterferons, the rate of sustained virologic response is suboptimal in cirrhotic patients, relative to non-cirrhotic patients. However, the treatment of patients with compensated cirrhosis has recently been encouraged by expert panels. Interferon-based therapy may provide additional benefit by reducing the risk of hepatocellular carcinoma in cirrhotic patients as suggested in preliminary studies. Results of two ongoing prospective studies are awaited to answer the important question of the effectiveness of suppressive interferon therapy, even in the absence of sustained virologic response. Given the importance of recurrent HCV following liver transplantation, attention has been directed toward the antiviral treatment of patients with advanced liver disease. This approach needs to be pursued with caution given the potential morbidity of the therapy. Recently, a low accelerating dosage regimen has provided excellent results and is the subject of additional inquiry.

Key words: hepatitis $\mathrm{C}$ virus, cirrhosis, liver transplantation, antiviral therapy

\section{Treatment in compensated cirrhosis}

The response to interferon-based therapy for patients with compensated cirrhosis due to hepatitis $C$ has been evaluated in several trials, both as the focus of prospective study, as well as in subgroup (post hoc) analyses of large registration trials. Despite the improved efficacy of peginterferons, the sustained virological response (SVR) rate is suboptimal in cirrhotic patients, relative to noncirrhotic patients. However, the treatment of patients with compensated cirrhosis has recently been encouraged by the International Liver Transplant Society Expert Panel in 2003 which concluded that patients with relatively compensated cirrhosis, defined by a MELD score of 18 or less, are acceptable treatment candidates. [1]

The likelihood of achieving an SVR with interferonbased therapy in cirrhotic patients can be deduced from prior studies which focused upon, or incorporated patients with, advanced fibrosis. Arguably, the most important trial on this issue was conducted by Heathcote and colleagues in patients with advanced stage fibrosis or cirrhosis. [2] Patients were randomized to peginterferon $\alpha-2 a$, at one of two doses (90 mcg or 180 mcg weekly), or standard interferon. Two thirds of those entered had cirrhosis. The SVR rate was greatest for those treated with peginterferon alpha-2a $180 \mathrm{mcg}$ weekly for 48 weeks $(30 \%)$; this is in comparison to a SVR rate of only $8 \%$ in those treated with standard, thrice weekly, interferon. In subgroup analysis comparing those with bridging fibrosis to those with cirrhosis, there did not appear to be a statistically significant difference between the groups in terms of achieving an SVR. The patients infected with genotype 1 who received the $180 \mathrm{mcg}$ dose of pegylated interferon had a $12 \%$ SVR rate, in comparison to $51 \%$ nontype 1 genotypes treated with this dose.

Further analysis of data from the Heathcote trial revealed that treatment was associated with histological improvement, especially in the group that experienced an
SVR. Comparing the pegylated interferon group (180 mcg) group to standard interferon, histological improvement occurred in $54 \%$ and $31 \%$ respectively. Pertinent to the issue of histological effects of therapy, Poynard pooled data retrospectively from 4 large randomized controlled trials that included paired biopsies. [3] This analysis included data on 3,010 patients treated for either 24 or 48 weeks. Overall, improvement in both the inflammatory grade and histologic stage of disease were associated with therapy. Longer duration of therapy strengthened this association. Of the 153 cirrhotic patients with SVR included in this analysis, 75 (49\%) had significant improvement in fibrosis after treatment.

Interferon-based therapy may provide additional benefit by reducing the risk of hepatocellular carcinoma in cirrhotic patients as suggested in preliminary studies. In a study among 103 patients with HCV-related cirrhosis, those receiving interferon had a lower incidence of hepatocellular carcinoma and improved survival after 4 years. [4] A reduction in the risk for hepatocellular carcinoma in cirrhotic patients was also detected in a Japanese trial of patients on interferon monotherapy for a median of 3 years. [5] Therefore, in addition to establishing a target for therapeutic efficacy in patients with advanced fibrosis, early studies suggest potential histological and survival benefits of interferon-based treatment.

Insight into the efficacy of combination therapy with pegylated interferon and ribavirin in cirrhotic patients can be obtained from the large registration trials for pegylated interferon. In the peginterferon alfa- $2 b$ registration trial, the $6 \%$ of participants that had cirrhosis demonstrated a lower SVR rate compared to those study subjects without cirrhosis. [6] Cirrhotic patients treated with pegylated interferon alfa- $2 \mathrm{~b}, 1.5 \mathrm{mcg} / \mathrm{kg}$ weekly in plus ribavirin 800 mg a day for 48 weeks had a $44 \%$ SVR; in comparison, patients treated with standard interferon alfa-2b, 3 million 
units three times a week plus ribavirin for 48 weeks had a slightly lower response rate of $41 \%$. In the second published pivotal trial of combined therapy with pegylated interferon and ribavirin, cirrhotic patients treated with peginterferon alfa-2a plus ribavirin for 48 weeks had SVR rate of $43 \%$, compared to $33 \%$ in patients treated with standard interferon combined with ribavirin. Non-cirrhotic patients enrolled into this study had SVR rates of $58 \%$ and $46 \%$ respectively. [7]

Results of two ongoing prospective studies are awaited to answer an important question that remains; is there any benefit of prolonged treatment of patients with advanced fibrosis or cirrhosis, even in the absence of SVR? The National Institutes of Health sponsored HALT-C trial (Hepatitis C Antiviral Long Term Treatment against Cirrhosis), is a multicenter study of the potential benefit of prolonged peginterferon therapy in mitigating the progression of fibrotic liver disease. [8] In this study, 391 of the 1045 patients enrolled into the initial "lead-in" phase had biopsy proven cirrhosis. Preliminary results show that cirrhosis alone impaired response to therapy, with lower SVR rates compared to non-cirrhotic patients. [9] In the COPILOT study (Colchicine Versus PEG-Intron Long Term), enrollees are predominantly cirrhotic patients who failed prior treatment. [10] An interim analysis suggested a benefit to pegylated interferon therapy, over colchicine, in reducing complications associated with cirrhosis. Long term outcome data from this trial and other suppressive protocols will determine the efficacy of such an approach. [11]

In summary, patients with advanced fibrosis or cirrhosis have a lower SVR compared to non-cirrhotic patients, even with the latest combination therapy. However, existing data support therapy of the patient with compensated cirrhosis. Cirrhotic patients may tolerate therapy less well, given the propensity for thrombocytopenia and leucopenia, as was seen in the three large trials that included cirrhotic patients. $[2,4,11]$ In practice, growth factors are commonly used to counter the treatment related cytopenias. The use of these agents is costly and has not been studied rigorously in a randomized controlled format to assess their value and impact on efficacy of therapy although they are now widely used in patients receiving interferon therapy.

\section{Treatment of advanced liver disease}

Chronic HCV infection is the leading indication for liver transplantation (LT) in the United States and Europe. Given the accelerated progression of HCV following LT, the observation than higher pre-transplant viral load is associated with poorer transplant outcome, and the difficulties in treatment of the infection following LT [12], it is reasonable to emphasize the importance of pretransplant treatment of $\mathrm{HCV}$. The International Liver Transplantation Society Expert Panel provided guidelines when considering interferon-based treatment in patients with HCV-cirrhosis. As seen in Table 1, this group advises treatment even in some patients with advanced cirrhosis.
Table 1. International Liver Transplantation Society Expert Panel Consensus Conference proposed guidelines for interferonbased treatment of patients with cirrhosis [1]

\begin{tabular}{|c|c|c|}
\hline Consider Treatment & CTP Score & MELD Score \\
\hline Strongly consider & $\leq 7$ & $\leq 18$ \\
\hline In select cases & $8-11$ & $18-25$ \\
\hline Treatment not advised & $>11$ & $>25$ \\
\hline
\end{tabular}

Clearly, there are major obstacles toward treatment of this group of patients. Since the advent of MELD-based allocation, with the associated lessened importance of waiting time, those awaiting liver transplant are more ill. The resulting poor synthetic function, presence of hepatic encephalopathy and hypersplenism limit the candidacy of patients for interferon-based therapies. Pre-transplant $\mathrm{HCV}$ treatment enthusiasm has also been curbed by the lower rates of sustained virologic response in those with fibrotic disease compared to those with less severe histology. Several advances in HCV therapy have allowed incremental progress in overcoming these hurdles. As described above, peginterferons have shown better efficacy that unmodified interferons in the treatment of cirrhotic stage HCV. [2] Additionally, the use of growth factors, specifically G-CSF and erythropoietin, has allowed more aggressive dosing of interferon and ribavirin. [13, 14] Finally, growing experience with antiviral therapy in this high-risk group has led to novel approaches and increasing success. Table 2 provides details on the published results of antiviral therapy in this difficult-to-treat population.

Table 2. Summary of results from interferon-based treatment regimens in patients with advanced liver disease

\begin{tabular}{|c|c|c|c|c|c|c|c|c|c|c|}
\hline & ref year & regimen & N & G1 & $\begin{array}{c}\text { CPT } \\
\text { B/C }\end{array}$ & $\begin{array}{c}\text { CPT } \\
\text { mean }\end{array}$ & ETR SVR & Dose reduction \\
\hline VanThiel & 13 & 1995 & $5 \mathrm{MU} /$ day & 30 & - & - & - & $56 \%$ & $46 \%$ & - \\
\hline Crippin & 15 & 2002 & various & 15 & $85 \%$ & - & 11.9 & $33 \%$ & - & $0 \%$ \\
\hline Thomas & 16 & 2003 & $5 \mathrm{MU} /$ day & 20 & $67 \%$ & $80 \%$ & 10 & $60 \%$ & $20 \%$ & $15 \%$ \\
\hline Forns & 17 & 2003 & $\begin{array}{c}\text { MUU/day } \\
\text { RBV 800 }\end{array}$ & 30 & $83 \%$ & $50 \%$ & - & $30 \%$ & $20 \%$ & $63 \%$ \\
\hline Everson & 18 & 2005 & LADR & 124 & $70 \%$ & $55 \%$ & 7.4 & $46 \%$ & $24 \%$ & $22 \%$ \\
\hline
\end{tabular}

Early published results with interferon/ribavirinbased regimens were unfavorable, leading to concern for the safety of such an approach. Crippin and colleagues randomized end-stage liver disease patients on the transplant waiting list to three dose regimens: interferon alfa-2b, 1 million units (MU) daily, interferon alfa-2b 3MU t.i.w., and interferon alfa-2b $1 \mathrm{MU}$ daily with ribavirin 400 mg PO BID. [15] These very sick patients (CPT mean 11.9) were subject to strict eligibility requirements: platelet count $>45,000 / \mathrm{mL}$, Hemoglobin $>11 \mathrm{~g} / \mathrm{dL}$, and absolute neutrophil count $(\mathrm{ANC})>1250 / \mathrm{mL}$. Dose reductions or study discontinuation were mandated for ANC $<750 / \mathrm{mL}$ or platelets $<45,000 / \mathrm{mL}$ and $\mathrm{ANC}<500 / \mathrm{mL}$ or platelets $<20,000 / \mathrm{mL}$, respectively. Ribavirin dose was decreased for hemoglobin $<10 \mathrm{~g} / \mathrm{dL}$ and discontinued for hemoglobin $<8.0 \mathrm{~g} / \mathrm{dL}$. Of those patients screened, $47 \%$ met entry criteria (most excluded for thrombocytopenia) of whom $33 \%(5 / 15)$ cleared virus on treatment. Of two patients that went to LT, one was a responder, but relapsed. Of concern was the safety profile: 20 severe adverse drug reactions were reported, including two serious infections, one of which led to multi-organ system 
failure and death. Enrollment was discontinued well short of intentions because of these complications.

Despite this setback, enthusiasm for pre-transplant therapy was rekindled by additional studies. Thomas and colleagues reported their experience with high-dose unmodified interferon monotherapy in 2003. [16] This report was similar to a similar protocol used in 1995 by the same principal investigator. [13] Of the 20 patients who were given interferon alfa-2b, 5MU/day subcutaneously, $60 \%$ cleared virus on therapy and $20 \%$ had SVR. Of those that cleared virus, 33\% remained nonviremic after liver transplantation. This regimen, which employed G-CSF to maintain ANC > 1500 cells/mL was well tolerated, with temporary dose discontinuation in $3 / 20(15 \%)$.

Forns and colleagues used relatively high-dose interferon/ribavirin therapy in their cohort of 30 patients awaiting transplantation in Spain in an effort to reduce viral load at the time of LT. [17] When the investigators estimated 4 months remained until transplantation, interferon alfa-2b $3 \mathrm{MU} /$ day and ribavirin $800 \mathrm{mg} /$ day were initiated, with a resulting mean treatment period of 12 weeks in 30 patients. The virologic response rate on therapy was $30 \%$, with two-thirds of responders remaining non-viremic after LT. As in other such trials many wait-listed patients did not meet eligibility requirements $(38 \%)$, and side effects were common. Despite the use of G-CSF and erythropoietin, dose reduction of interferon was required in $60 \%$, while ribavirin dose was decreased in $23 \%$ of study patients.

Everson and colleagues offer the largest series to date with a unique low accelerating dosage regimen (LADR). [18] One hundred twenty four patients were treated with unmodified interferon or peginterferon at low initial dose, with increases every two weeks toward standard target doses. Duration of therapy was intended to be 24 weeks in genotypes 2 and 3 and 48 weeks in genotype 1 infection. Hematologic inclusion criteria included ANC $>800$ cells $/ \mathrm{mL}$, hemoglobin > $10 \mathrm{~g} / \mathrm{dL}$ and platelets > $35,000 / \mathrm{mL}$. Growth factors were allowed in the management of therapy-induced cytopenias. The investigators estimated that "one fourth to one sixth of the patients referred to our clinic with advanced liver disease were treated with LAD during his period." End of treatment response was seen in $46 \%$ while the SVR rate was $22 \%$. SVR was associated with non- 1 genotype, CPT class A, and a complete course of therapy. As expected in this very ill set of patients, adverse drug reaction rates were relatively common, with two such events potentially contributing to patient mortality. Of the 15 patients that were virologically negative at the time of transplantation, 12 remained $\operatorname{HCV}(-)$ for at least six months following LT.

Although the data are mixed on the effectiveness and safety of interferon-based therapies in patients with decompensated cirrhosis, the demonstrated possibility of viral eradication in this group with possible improvement in hepatic synthetic function and improved posttransplant outcome provide an important rationale for further studies in this area. Future work will focus on pegylated accelerating dose regimens, the increased use of growth factors and non-interferon based antiviral therapies. Currently, it is advisable to treat such patients only in experienced centers with close monitoring for adverse events. [1, 19]

\section{Research Direction}

The morbidity of recurrent HCV following liver transplantation has made pre-transplant antiviral therapy a high priority for research. The low accelerating dosage regimen of Everson and colleagues has demonstrated good efficacy but must be replicated in other cohorts and centers. The development of new, nonimmunomodulatory antiviral agents promises to be a significant advance in the treatment of this population. Ultimately, individualization of the anti-viral regimen chosen in each case may lead to better efficacy rates with less adverse drug reactions and side-effects.

\section{Acknowledgements}

The authors acknowledge Paul Martin, MD for his reading of and comments on the manuscript.

\section{Conflict of Interest}

The authors have declared that no conflict of interest exists.

\section{References}

1. Wiesner RH, Sorrell $\mathrm{M}$, Villamil F. International Liver Transplantation Society Expert Panel. Report of the first International Liver Transplantation Society expert panel consensus conference on liver transplantation and hepatitis C. Liver Transpl 2003;9:S1-9.

2. Heathcote EJ, Shiffman ML, Cooksley WG, Dusheiko GM, Lee SS, Balart L, Reindollar R, Reddy RK, Wright TL, Lin A, Hoffman J, De Pamphilis J. Peginterferon alfa-2a in patients with chronic hepatitis $\mathrm{C}$ and cirrhosis. N Engl J Med 2000;343:1673-80.

3. Poynard T, McHutchison J, Manns M, Trepo C, Lindsay K, Goodman $\mathrm{Z}$, Ling $\mathrm{MH}$, Albrecht J. Impact of pegylated interferon alfa- $2 \mathrm{~b}$ and ribavirin on liver fibrosis in patients with chronic hepatitis C. Gastroenterology 2002;122:1303-13.

4. Serfaty L, Aumaitre H, Chazouilleres O, Bonnand AM, Rosmorduc $\mathrm{O}$, Poupon RE, et al. Determinants of outcome of compensated hepatitis C virus-related cirrhosis. Hepatology 1998;27:1435-1440.

5. Kasahara A, Hayashi N, Mochizuki K, Takayanagi M, Yoshioka K, Kakumu S, Iijima A, Urushihara A, Kiyosawa K, Okuda M, Hino K, Okita K. Risk factors for hepatocellular carcinoma and its incidence after interferon treatment in patients with chronic hepatitis C. Hepatology 1998;27:1394-1402.

6. Manns MP, McHutchison JG, Gordon SC, Rustgi VK, Shiffman M, Reindollar R, Goodman ZD, Koury K, Ling M, Albrecht JK. Peginterferon alfa- $2 \mathrm{~b}$ plus ribavirin for initial treatment of chronic hepatitis C: a randomised trial. Lancet 2001;358:958-965.

7. Fried MW, Shiffman ML, Reddy KR, Smith C, Marinos G, Goncales FL Jr, Haussinger D, Diago M, Carosi G, Dhumeaux D, Craxi A, Lin A, Hoffman J, Yu J. Peginterferon alfa-2a plus ribavirin for chronic hepatitis C virus infection. N Engl J Med 2002;347:975-82.

8. Lee WM, Dienstag JL, Lindsay KL, Lok AS, et al. Evolution of the HALT C Trial: pegylated interferon as maintenance therapy for chronic hepatitis $C$ in previous interferon nonresponders. Control Clin Trials 2004;25:472-92.

9. Everson GT, Hoefs JC, Malet $\mathrm{P}$, et al. Impaired virologic response in patients with advanced liver disease due to chronic hepatitis $C$ is independently linked to severity of disease; results from the HALT-C trial. Hepatology 2004;40:180A.

10. Afdhal N., Freilich B., Levine R., Black M., et al. Colchicine versus Peg-Intron Long Term (COPILOT) trial: Interim analysis of clinical outcomes at year 2. Hepatology 2004;40:238A.

11. Poynard T, et al. Sustained virologic response (SVR) in the EPIC3 trial: week twelve virology predicts SVR in previous interferon/ribavirin treatment failures receiving peg-intron/rebetol (PR) weight based dosing (WBD). In: 40th Annual meeting of the European Association for the Study of Liver Disease; April 13-17, 2005; Paris, France. 
12. Charlton M, Seaberg E, Wiesner R, Everhart J, Zetterman R, Lake J, Detre K, Hoofnagle J. Predictors of patient and graft survival following liver transplantation for hepatitis C. Hepatology 1998;28:823-30

13. Van Thiel DH, Faruki H, Friedlander L, Fagiuoli S, Caraceni P, Molloy PJ, Kania RJ, Wright HI. Combination treatment of advanced $\mathrm{HCV}$ associated liver disease with interferon and G-CSF. Hepatogastroenterology 1995;42:907-12.

14. Pockros PJ, Shiffman ML, Schiff ER, Sulkowski MS, Younossi Z, Dieterich DT, Wright TL, Mody SH, Tang KL, Goon BL, Bowers PJ, Leitz G, Afdhal NH; PROACTIVE Study Group.. Epoetin alfa improves quality of life in anemic $\mathrm{HCV}$-infected patients receiving combination therapy. Hepatology 2004;40:1450-8.

15. Crippin JS, McCashland T, Terrault N, Sheiner P, Charlton MR. A pilot study of the tolerability and efficacy of antiviral therapy in hepatitis $C$ virus-infected patients awaiting liver transplantation. Liver Transpl 2002;8:350-5.

16. Thomas RM, Brems JJ, Guzman-Hartman G, Yong S, Cavaliere P, Van Thiel DH. Infection with chronic hepatitis $C$ virus and liver transplantation: a role for interferon therapy before transplantation. Liver Transpl 2003;9:905-15.

17. Forns X, Garcia-Retortillo M, Serrano T, Feliu A, Suarez F, de la Mata M, Garcia-Valdecasas JC, Navasa M, Rimola A, Rodes J. Antiviral therapy of patients with decompensated cirrhosis to prevent recurrence of hepatitis C after liver transplantation. J Hepatol 2003;39:389-96.

18. Everson GT, Trotter J, Forman L, Kugelmas M, Halprin A, Fey B, Ray C. Treatment of advanced hepatitis $C$ with a low accelerating dosage regimen of antiviral therapy. Hepatology 2005;42:255-62.

19. Strader DB, Wright T, Thomas DL, Seeff LB. AASLD practice guideline: diagnosis, management, and treatment of hepatitis $C$. Hepatology 2004;39:1147-1171. 